\title{
The Health Authorities Bill
}

\section{Great care will be needed to avoid exacerbating unresolved and destructive tensions}

Behind the Health Authorities Bill (about to complete its parliamentary stages) seethes a mass of unresolved tensions. On the face of it, all the bill will do is streamline the upper echelons of management in the NHS. It follows a major review of the NHS in $1993,{ }^{1}$ which recommended that to refine the internal market the NHS should replace the old regional tier with eight new regional offices of the central NHS Executive and should enable the formation of local commissioning agencies from merged district health authorities and family health services authorities. ${ }^{2}$

Yet these small readjustments in bureaucracy will highlight at least three substantial areas of contention that are already pulling the NHS in different directions. Firstly, what will be the balance of power between the central NHS headquarters and the front line? Secondly, who will hold sway in the local purchasing of health care -the health commissions or the fundholding general practitioners - and will it really be led as intended by primary care? Thirdly, how will the decisions be made-by the market, by political forces, or by scientific evidence?

These three sets of interrelated opposing tensions threaten to undermine what would otherwise be the next logical step in improving how the service is organised. Concerns about the bill have also centred on more detailed matters such as who will hold junior doctors' contracts as they rotate among trusts, how postgraduate and continuing medical education will be coordinated, whether regional directors of public health will be compromised by becoming civil servants, how cancer registries and other regional services will be run, who will sit on the new health authorities, how accountable they will be to the local population, and how they will receive statutory professional advice. Some of these objections are simply wrinkles to be ironed out, but many are symptoms of deeper problems.

Will policymaking be centred on the NHS Executive and its eight new regional offices or pushed down to the local negotiations between commissioners, general practitioners, and trusts? The new legislation will strengthen both the centre and the front line. The current political intention is that the centre should apply only a light touch, allowing the local internal market, and in particular the commissioners, to exert strong leverage to improve health services. Purchasers will find themselves ever more able to exert real muscle in negotiating the services to be provided by their trusts. Yet at the same time they will also be more directly accountable through the regional offices to the centre. The bill introduces a clearer command structure, potentially opening the doors to stronger central control.

According to management gurus, ${ }^{34}$ such an arrangement can be an excellent way to run an organisation if the centre genuinely sets an overall visionary direction and empowers those in the front line to take the initiative to make things happen. But words like "visionary" and "empowering" have not always been the hallmarks of NHS management. If the new regional offices turn into mechanistic target setters and nit picking progress checkers the result will be heavyhanded bureaucracy and unproductive paperchases that will not only fell forests but further demoralise the service. On the other hand, if "light touch" translates as "laissez faire" the result will be anarchy, with a resulting fragmentation that will please nobody-least of all a public that expects a unified NHS. It is by helping to set clear and well founded policies and working supportively with the commissioners and health professionals further down the line that the new regional offices will best serve the NHS Executive's aim of achieving genuine progress in the organisation of care.

The bill could also add to the growing tensions at the local level, not only between health commissions and general practitioner fundholders but between providers of primary, community, and hospital care. The new health commissions, with a fresh emphasis on primary care, are to lead the purchasing of health care for their populations of about half a million people each. Much has been written about the potential for fundholders to undermine that role. ${ }^{5}$ That potential will increase as more of the budget passes down to fundholders, ${ }^{6}$ allowing them to negotiate separately with trusts over a widening range of services. This trend to reduce the direct purchasing power of commissions seems set to continue. At the same time, however, the bill will ensure that the health commissions increase their strategic involvement in primary care and their hold over general practitioners whose contracts they will administer and whom they will hold accountable for their purchasing.

The call for "primary care led purchasing" thus conceals an ambiguity. Will the leadership come from the general practitioners themselves or from the health commissions? That very question raises the old spectre of mistrust between doctors and managers, a spectre that will need to be carefully laid to rest if the government's intentions of close collaboration between fundholders and health commissions is to be realised. The NHS Executive, ever hopeful, calls for "a growing partnership between health authorities and GPs." But the 
BMA's current rejection of merged authorities monitoring fundholders because they are "in effect, competing purchasers" does not augur well. Nor does the anxiety among general practitioners and family health services authorities that the new mergers will swamp the interests of primary care with the concerns of hospital services (an anxiety sometimes matched by hospitals' insecurity that health commissions will become too immersed in primary care). We will need much careful work to build the necessary trust between these competing and mutually suspicious local forces if we are to see the genuinely integrated primary and secondary services that the bill intends.

The third set of tensions is between politically determined demand and scientifically founded evidence. There are often strongly differing views about the extent to which a particular service should be available. Previously it was easy-doctors knew best. Recently, however, the situation has changed as purchasers, providers, and other professionals and practitioners-not to mention the pharmaceutical industry, politicians, press, pressure groups, public, and patients-are taking a much greater role in shaping policy. Moreover, it is becoming increasingly clear that they are right to question the doctors because there is a dearth of evidence of the effectiveness, let alone cost effectiveness, of most medical activity. ${ }^{9}$

Yet all the parties in such debates base most of their views on beliefs, not evidence. Given that under the new legislation many of the protagonists will, as described above, gain more scope to pursue their own interests, there is obvious potential for adding to the strain between them. Perhaps the key to the bill's success will lie in the increasing commitment to health services research and development, to continuing professional education, to evidence based medicine, ${ }^{10}$ and to more open access to knowledge. The more the NHS invests in increasing its knowledge base the less are the political debates likely to split it asunder. In short, if the new legislation is to work despite the underlying tensions it will need to be very carefully managed. Coupled with greater trust, better communication, and above all a genuine commitment to knowledge based decisions, it could set an international example for managed care organisations. The NHS cannot afford to get this wrong.

JOHN GABBAY Professor

Wessex Institute of Public Health,

University of Southampton,

Southampton General Hospital,

Southampton SO16 6YD

1 Department of Health. Managing the new NHS: proposals to determine the new NHS regions and establish new regional health authorities. London: DoH, 1993.

2 Department of Health. Managing change: the NHS and the Department of Health. London: DoH, 1994.

3 Kanter EM. When giants learn to dance. London: Routledge, 1990

4 Moss Kanter R, Bennis W. Beyond leadership: balancing economics, ethics and ecology. Oxford: Blackwell, 1994.

5 Glennester H. Implementing GP fundholding. Wild card or winning hand? London: Open University Press, 1994.

6 NHS Executive. Towards a primary care led NHS. Leeds: NHSE, 1994. (E/L 94/78.)

7 NHS Executive. Gerald Malone launches new accountability framework for GP fundholding. Leeds: NHSE, 1994. (Press release.)

8 BMA. Health Authorities Bill (bill number 2). Second reading debate in House of Commons. London: BMA, 1994.

9 Smith R. Where is the wisdom? BMF 1991;303:798.

10 Davidoff F, Haynes B, Sackett D, Smith R. Evidence based medicine. BMF 1995;310:1085.

\section{Psychological care of medical patients}

\section{Time to recognise the need and provide services}

People with appreciable physical illness have at least twice the rate of psychiatric disorder found in the general population, with a concomitant increase in clinically important disorders that just fail to meet standard diagnostic criteria. The main problems are mood disorder, ${ }^{1-3}$ cognitive impairment, ${ }^{45}$ substance misuse, ${ }^{67}$ and abnormal illness behaviour or somatisation. ${ }^{89}$ These disorders are clinically and personally important: they impair quality of life; reduce the ability to adhere to, or benefit from, treatment for medical conditions; and are associated with a poor outcome of treatment for physical illness. Episodes of medical care are more complex and costly in those whose physical disorder is accompanied by psychiatric comorbidity. ${ }^{10}$

Effective treatments exist for psychiatric disorder in physically ill people, which are remarkably cheap for the benefits they provide. In fact, the costs of providing psychiatric treatment in a medical setting may be more than met by the savings that result from reductions in inappropriate medical investigation and treatment-the so called cost offset effect. ${ }^{11}$

Unfortunately, few hospitals arrange formal services to meet the psychological needs of their patients. Instead they rely on a mixture of informal provision in some areas and neglect in others. This approach may be unsustainable in future. Existing working relationships between psychiatrists and general hospital doctors are under strain as the health service reforms have placed most mental health services in different trusts from general hospitals. The emphasis on community care in psychiatry means that psychiatrists spend less of their working week in hospitals, so the opportunities for informal contact with colleagues are diminished. Until recent years many people with chronic mental illness and coexisting physical illness could be treated in psychiatric hospitals. Now, pressure on beds in both psychiatry and general medicine makes the already difficult task of caring for patients with coexisting mental and physical illness harder. At the same time, the growth of consumerism in medicine and heightened public awareness of the psychological aspects of physical illness add to the demand for relevant services.

\section{Daunting agenda}

In response to the perceived gap between the needs for, and availability of, psychiatric services in general hospitals the Royal College of Psychiatrists and the Royal College of Physicians have jointly published a report on the psychological care of medical patients. ${ }^{12}$ This is not a bland appeal to the principles of holistic care but a bench manual for those who plan and deliver services. The working group has tackled many practical aspects of the psychological care of medical patients, and the agenda it sets the profession is daunting.

Physicians, surgeons, and general nurses need the skills to identify psychological problems in their patients, to offer appropriate psychological care, and to know when and how to refer for psychiatric help. When a referral is made it needs to be picked up by a psychiatric service that understands the complexity of physical and psychiatric comorbidity and can deliver appropriate treatments that are accessible and acceptable to the referring agent, the other staff working in the general hospital, and the patient.

Fortunately, the working group's report includes sections 